\title{
Liderança e mudança: \\ o caso educacional de \\ jovens moradores de favelas
}

\author{
Ignez Martins Tollini
}

\section{Resumo}

Este trabalho tem o objetivo de analisar o caso educacional de adolescentes moradores em favelas, alunos de uma escola municipal no Rio de Janeiro. Foi argumentado que tal tarefa educacional requer liderança efetiva para encorajar mudança de atitude, valores e comportamento de adolescentes, como proposto no Modelo Fullan. Este modelo permitiu a reinterpretação do caso educacional tratado neste estudo, caracterizado por uma "teorização" baseada em conhecimento, criatividade, insight, e bom senso. Espera-se que este estudo inspire políticas educacionais para jovens que vivem em favelas e periferias urbanas e possa ser reproduzido em outras situações.

Palavras-chave: Liderança. Mudança. Educação.

\section{Abstract}

Leadership and change: the educational case of adolescents living in slums

This paper has the objective of analyzing the educational case of adolescents living in slums, students of a municipal school in Rio de Janeiro. It has been argued that it is a difficult task that requires effective leadership to encourage a change in attitude, values and behavior of adolescents, such as proposed in the Fullan Model. This model allowed the reinterpretation of the case addressed in this study, characterized by a "theorization" based on knowledge, creativity, insight, and common sense. It is expected that this study will inspire educational policies for adolescents living in slums and urban periphery, and may be replicated in other situations.

Keywords: Leadership. Change. Education.
Resumen

Liderazgo y cambio: el caso educacional de jóvenes moradores de chabolas 
Este trabajo tiene por finalidad evaluar el caso educacional de adolescentes favelados, estudiantes de una escuela municipal en Rio de Janeiro. Há sido argumentado que la tarea educacional requiere liderazgo efectivo para estimular cambio de actitud, valores y comportamiento de adolescentes, como propuesto en el Modelo Fullan. Este modelo ha permitido la reinterpretación del caso educacional tratado en este estudio, caracterizado por una "teorización" basada en conocimiento, creatividad, insight, y senso común. Espera-se que este estúdio inspire políticas educacionales para jóvenes moradores de chabolas e periferias urbanas y pueda ser reproducido en otras situaciones.

Palabras clave: Liderazgo. Cambio.

Educación

\section{Introdução \\ Problema, objetivo, argumentos e organização}

Adolescentes brasileiros das periferias urbanas freqüentam a escola, mas continuam sem orientação para vida. Este trabalho tem como objetivo analisar esse problema, especificamente o caso educacional dos adolescentes moradores de favelas, alunos de uma escola municipal do Rio de Janeiro.

Argumenta-se que, estimular mudança de atitudes, valores e comportamentos de adolescentes é tarefa muito difícil que exige liderança efetiva, tal como a proposta no modelo Fullan. Argumenta-se, também, que no caso tratado no presente trabalho, a educação dos alunos caracteriza-se por uma "teorização" baseada em sabedoria, criatividade, insight, e bom senso.
O trabalho é organizado nas seguintes seções: o Modelo Fullan; o perfil da educadora Irmã Anne Marie Paternot; o caso educacional dos adolescentes favelados, com a redefinição do problema, argumentos e análise e conclusão e recomendações. Em anexo estarão os textos escritos pela religiosa educadora e as avaliações dos alunos.

\section{O Modelo Fullan}

Este modelo foi concebido por Michael Fullan (2001), Diretor do Instituto para Estudos em Educação da Universidade de Toronto, Canadá, reconhecido internacionalmente como uma das maiores autoridades mundiais nas áreas de liderança e mudança organizacional.

Fullan concebe liderança de maneira nunca apresentada anteriormente. Outros autores elaboraram modelos que contemplam aspectos multidimensionais de liderança. Entretanto, nunca havia sido estabelecida relação entre a complexidade da liderança e a complexidade da mudança, como no modelo Fullan. Para ele, liderança é essencial em um processo de mudança. Isto porque o administrador ou gestor tem que enfrentar demandas organizacionais muito mais exigentes em um processo de mudança do que no dia a dia da organização. É em um processo de mudança que o administrador tem que mostrar suas qualidades de liderança para enfrentar as forças que provocam turbulências nas organizações.

Não existe, no modelo Fullan, a conotação entre a idéia de liderança e a idéia de autoritarismo ou inflexibilidade. $\bigcirc$ líder é concebido como alguém cuja autoridade é baseada em competência para guiar as pessoas da organização durante a mudança. Não basta que o administrador desenvolva uma 
das habilidade de liderança, mas sim um conjunto integrado delas. A razão é que as dimensões de liderança, concebidas por Fullan, são interdependentes. $\bigcirc$ autor chega a este entendimento após longos anos de observações em organizações, mormente as educacionais. Fullan iniciou estudos específicos de liderança e mudança quando os estudos sobre organização começavam a ser influenciados pelos aportes advindos das ciências sociais, principalmente a psicologia e a sociologia. Até os meados do século vinte, as idéias de Fayol (apud GULICK et al., 1937) e Taylor (1911), dominavam a teoria da administração. Após essa época, os teóricos descobriram que pessoas eram importantes nas organizações. Isto se deu principalmente após o experimento de Hawthorne' ${ }^{1}$, nos Estados Unidos. Este momento marcou, também, o surgimento do interesse pela criação de clima de bem-estar nas organizações. No campo da educação, este clima organizacional foi considerado importante para a aprendizagem do aluno.

Estudos seguintes abriram novas questões sobre os efeitos da mudança nas organizações e nas pessoas. Passou-se a entender que a cultura das organizações era formada por fatores endógenos e exógenos a elas. A partir dos anos 80, Fullan explorou estas idéias em seus trabalhos sobre forças influenciadoras da mudança nas organizações educacionais.

A partir dos anos 90, Fullan e vários outros acadêmicos têm produzido trabalhos sobre a quebra da estabilidade nas organizações e seus efeitos sobre os sentimentos das pessoas que estão nelas. Como ensina a veIha, e sempre nova, teoria de sistemas, a cri- se produzida pela instabilidade é necessária para renovação, crescimento e adaptação das organizações a novas circunstâncias.

Outro interesse na trajetória acadêmica de Fullan diz respeito à formação de sistemas sociais e políticos interconectados por redes velozes de comunicação. $\bigcirc$ fenômeno das comunicações imediatas insinua a possibilidade de mudanças organizacionais aparentemente mais rápidas e mais fáceis. Fullan aponta que as mudanças materiais se fazem em ritmo mais rápido do que a mudança de valores, comportamentos e sentimentos das pessoas. A mudança de valores e comportamentos é tarefa complexa e continua a desafiar os administradores das organizações. Para lidar com esses desafios, Fullan propõe um modelo de liderança composto de cinco dimensões.

A primeira dimensão - amplo "propósito moral" - perpassa as outras quatro dimensões. $\bigcirc$ autor não apresenta definição formal de "propósito moral". Prefere mostrar seu significado através de exemplos de ações desenvolvidas por líderes em um processo de mudança organizacional. Líderes que têm um propósito moral estão comprometidos com os objetivos da mudança e com as necessidades e sentimentos das pessoas envolvidas nela. Estes líderes não necessitam de estímulos externos, tais como regras, regulamentos, pressões, repreensões ou elogios para se comprometerem com a mudança. $\bigcirc$ líder comprometido com a mudança procura estimular o comprometimento interno das pessoas em processo de mudança organizacional. $\bigcirc$ líder é efetivo quando tem convicção que a mudança fará diferença positiva para a organização e as pessoas que estão nela.

\footnotetext{
1 EXPERIÊNCIA DE HAWTHORNE, feita nos Estados Unidos, por acadêmicos, em uma fábrica de relés de telefone na qual estava havendo queda de produtividade. Descobriu-se que a variável "relacionamento" entre os trabalhadores solucionou o problema e provocou a melhoria da produtividade na fábrica.
} 
A segunda dimensão de liderança, o "entendimento da mudança", ensina que se o líder tem propósito moral de iniciar e orientar a mudança terá que entendê-la. É comum que as pessoas sintam-se amedrontadas com a perspectiva de mudança. $O$ que é novo tem o poder de desequilibrar pessoas sensíveis ou que ignoram as finalidades da mudança. $O$ líder deve refletir sobre as facilidades e obstáculos que podem surgir no decorrer da mudança. Podem ser obstáculos de ordem material ou humana. O líder terá que entender as variadas reações das pessoas em face de obstáculos do primeiro tipo, os mais fáceis, e estar preparado para lidar com os do segundo tipo, os mais críticos. $\bigcirc$ entendimento desse segundo tipo de problema demandará que o líder desenvolva habilidades de relacionamento.

A terceira dimensão de liderança reconhece a necessidade do líder "construir relacionamentos". Para que a liderança seja efetiva, o líder terá que criar relacionamentos autênticos. Isto significa relacionamentos com base em respeito e querer bem. $\bigcirc$ autor diz que o líder organizacional não precisa chegar a ser como a Madre Tereza de Calcutá. Deve, entretanto, desenvolver suficiente habilidade para lidar com pessoas invejosas, mal humoradas, mentirosas, intrigantes que criam conflitos nas organizações. Se o líder tem compromisso interno com a mudança e entende o quanto ela afeta algumas pessoas, saberá ter empatia com a condição de pessoas difíceis. O líder saberá que o sucesso da mudança organizacional depende de sua habilidade pessoal de vencer as barreiras para boa convivência com e entre pessoas dentro e fora da organização. Portanto, ter um propósito moral e compreender os efeitos da mudança capacita o líder a entender e aten- der os seres humanos que necessitam de cuidados ao longo do processo de mudança. Para Fullan, relacionamentos não podem ser impostos, mas podem ser criados com sabedoria, paciência e boa vontade.

A quarta dimensão de liderança, "criar e compartilhar conhecimento",é intimamente ligada à dimensão "construir relacionamento". $\bigcirc$ conhecimento a que Fullan se refere em seu modelo, é o que vai surgindo na organização no decorrer do processo de mudança. $\bigcirc$ líder deve compartilhar este conhecimento com todas as pessoas envolvidas no processo. Quanto mais as pessoas aumentam seu conhecimento sobre a organização, mais se sentem participantes e à vontade neste processo. A mudança deve proporcionar contínua criação de conhecimentos, aí incluídas as oportunidades das pessoas adquirirem melhor conhecimento de si próprias e dos colegas na organização. Ironicamente, o compartilhamento de conhecimento é difícil de acontecer nas organizações educacionais. Segundo Fullan, os administradores educacionais e professores tendem a ser ciosos de seu conhecimento e hesitam em compartilhá-lo com seus pares. Por exemplo, escolas e faculdades, nas quais professores de uma área não trocam conhecimentos com seus colegas, perdem a oportunidade de melhorar suas contribuições para a aprendizagem dos alunos.

A quinta e última dimensão de liderança é o "estabelecimento ou construção de coerência" entre as outras quatro dimensões. Como é fácil intuir, esta dimensão tem uma conotação sistêmica. Fullan estabelece relação entre coerência e fragmentação na organização. Para o autor, a tendência central de sistemas dinâmicos complexos é estar constantemente causando fragmentação. Os 
líderes precisam aceitar essa condição como um fato e reconhecer seu valor potencial para construir coerência. Contudo, o líder não pode se esquecer que a coerência persistente é perigosa. A teoria geral de sistemas ensina que o equilíbrio persistente na organização é um precursor de morte (ou entropia da organização). Os líderes que procuram criar coerência não devem ter medo das perturbações que ocorrem no sistema (organização) em processo de mudança. Para Fullan, a coerência que conta não é a que está escrita, mas a que está na mente e no coração dos membros da organização. Portanto, quando Fullan diz que perturbação no sistema é uma coisa boa, isto não significa que ele esteja contra coerência. Justo o contrário, Fullan diz que processos causadores de instabilidade abrem caminho para atingir coerência em todas as partes da organização. Em outras palavras, a coerência mais poderosa na organização é uma função proveniente de se ter enfrentado as ambigüidades e complexidades de problemas difíceis de serem resolvidos.

Para finalizar esta seção, é preciso mencionar que, em trabalhos anteriores sobre o modelo Fullan (2001), Tollini (2003a, 2003b, 2003c, 2003d) relaciona idéias desse autor com as de outros acadêmicos contemporâneos. Por exemplo, Marris (1975), Getzels, Lipham e Campbell (1968), Egan (1974), Chin e Benne (1975) e Carlson (1965), avançaram a teoria sobre liderança ao longo da segunda metade do século vinte.

Na década de 90, dois outros autores também causavam impacto no campo da administração com seus trabalhos - a proposta de Peter Senge (1990) sobre as "organizações aprendizes" e o trabalho de Peter Drucker (1999) sobre a "nova sociedade do conheci- mento". Nota-se que a dimensão de liderança "construindo coerência", proposta por Fullan, apresenta fundamento teórico semeIhante ao da "quinta disciplina" proposta por Senge. Subjacente às duas proposições está a teoria geral de sistemas. Observa-se, também, que existe semelhança teórica entre a dimensão de liderança "criando e compartilhando conhecimento" e a proposição da "sociedade do conhecimento" de Drucker (2001).

Em uma cultura de mudança cada vez mais acelerada como a atual, onde várias informações estão disponíveis, onde as várias pessoas se comunicam pelo correio eletrônico, é natural que idéias transitem com mais vigor e rapidez do que décadas atrás. As ciências ganham com isso e também seus usuários.

Continuando o caminho proposto no presente trabalho, a próxima seção apresenta breve perfil da religiosa responsável pelo caso educacional dos adolescentes favelados.

\section{Breve perfil da Irmã Anne Marie Paternot e de sua obra educacional}

Mère Paternot, como é conhecida nos colégios onde foi Diretora, teve a iniciativa de ir à Escola Municipal Marc Ferrez, no Alto da Boa Vista, Rio de Janeiro, e se apresentar, como voluntária, para desenvolver um trabalho educacional com alunos e adolescentes das favelas. Esse ato, por si só, seria um caso singular.Todavia, torna-se ainda mais notável quando se conhece a história de vida de Anne Marie Paternot, a menina rica de Copacabana, educada na Europa, que aos 19 anos sentiu o desejo de dedicar sua vida a Deus e esperou a idade de 21 anos para realizar esse seu desejo. 
A história da vida e obra da educadora, a ser aqui apresentada, é baseada no senso comum da autora desse trabalho, que, aos onze anos de idade, teve o primeiro contato com Mère Paternot, no Colégio Sacré Coeur de Jesus, no Alto da Boa Vista, Rio de Janeiro. Diretora daquele internato de meninas da sociedade brasileira e internacional, colégio onde a língua oficial de conversação era o francês, Mère Paternot era vista como modelo de inteligência, cultura e finesse. Não era para menos, porque mostrava a rara capacidade de educar, sendo ao mesmo tempo exigente com a disciplina e compreensiva, humana no contato com as alunas. Seus conceitos educacionais eram já revolucionários. Sua administração conservava valores importantes na educação tais como a honestidade, o respeito a si mesmo e aos outros, a dedicação aos estudos, a vida espiritual profunda, a alegria, etc. Ao mesmo tempo, introduzia mudanças em aspectos educacionais adotados no "Sacré Coeur" que, para ela, pareciam coisas da "idade média" (palavras da educadora em recente entrevista).

Tendo visto de perto o pós-guerra na Europa e as conseqüentes necessidades de racionamento, ficou admirada ao ver que alunas brasileiras não se davam conta da sobriedade no comer, mormente quando os países europeus passavam por privações alimentares. A par de passar esses e outros valores para as alunas, tratou de mudar práticas pedagógicas que provocavam a obediência, mas não fortaleciam o entendimento da distinção entre o certo e o errado. Este foi é um ponto básico da filosofia educacional que Mére Paternot desenvolveu ao longo da segunda metade do século vinte. Seu modo de educar marcou as alunas que tiveram o privilégio de a terem como mestra.
Com o passar dos anos, Mère Paternot foi aperfeiçoando sua didática ao descobrir novos modos de educar. Tinha cada vez mais certeza que era importante dar às alunas oportunidade de iniciarem as ações, de discutirem em grupo suas idéias para então tomarem decisões sobre sua própria educação. Estava convencida que era importante criar um clima de bem-estar nas atividades educacionais, para que as alunas considerassem prazerosas essas atividades.

Mére Paternot desenvolveu sua filosofia educacional através da prática e da observação. Sem usar os termos da moda entre os educadores do século vinte, foi através do learning by doing que ela testava suas idéias. Deste modo, tentava entender fracassos na vida pessoal de ex-alunas, tanto do internato como dos diversos externatos do "Sacré Coeur". Comentava que aquelas alunas, que encontraram dificuldades na vida, souberam enfrentá-las com coragem e dignidade. Esses eventos foram matéria de reflexão, um tipo de feed back, para sua vasta obra educacional.

Com as aceleradas mudanças culturais no mundo, a partir dos anos 70, os tradicionais colégios internos foram desaparecendo, restando alguns externatos para meninas. Mère Paternot nunca pensou em se retirar da cena educacional. Continuou sua caminhada com o mesmo vigor, apesar de vários problemas de saúde e acidentes físicos que se sucederam nas últimas décadas. Hoje, aos 88 anos, completados em agosto deste ano, Mère Paternot relata, com o mesmo entusiasmo e alegria de uma jovem de vinte anos, sua última experiência educacional. Foi grande a surpresa de sua ex-aluna, ao saber para onde a antiga mestra estava dirigindo sua sabedoria. 
Havia informações que continuava a dar aulas de francês, para membros da família real brasileira, os jovens Orleans e Bragança. Nunca se poderia adivinhar ou imaginar que teria também dirigido sua atenção, nos últimos sete anos, para adolescentes das favelas cariocas.

\section{Caso educacional}

Para que se desenvolva análise científica do caso educacional dos adolescentes favelados, é necessário, primeiramente, redefinir o problema e os argumentos apresentados na Introdução deste trabalho.

\section{Redefinição do problema e argumentos}

A perspectiva teórica, examinada anteriormente, permite agora uma redefinição do problema central e dos argumentos focalizados neste trabalho. Essa definição é necessária para a análise rigorosa da inter-relação entre o caso educacional dos alunos adolescentes favelados e o modelo Fullan de liderança e mudança.

É importante relembrar que o problema central refere-se ao grande número de brasileiros adolescentes que vivem nas periferias urbanas e que, mesmo freqüentando a escola, continuam sem orientação para vida digna na sociedade.

Portanto, à luz da perspectiva teórica, o problema pode ser reinterpretado como:

- grande número de jovens brasileiros adolescentes que vivem nas periferias urbanas e que freqüentam escolas nas quais não existe liderança comprometida a ajudá-los a desenvolver capacidades essenciais para mudar sua precária condição de vida atual e para poderem efetivamente vir a participar da sociedade.

De acordo com os argumento centrais desse trabalho e à luz da perspectiva teórica, será dada atenção especial à proposição:

- a educação dos adolescentes favelados, a ser analisada, é desenvolvida por uma educadora líder com o propósito moral de criar relacionamento genuíno com os alunos, entender o que eles pensam sobre si mesmos e sua vida, ajudá-los a criar e compartilhar novos conhecimentos para mudar sua própria vida e ajudá-los a formar um quadro coerente de sua própria mudança.

A partir desse ponto, pretende-se testar os argumentos e as "áreas de sensibilidade". A análise da adequação do modelo Fullan para iluminar o caso educacional, criado por Mère Paternot, tem uma estrutura narrativa, isto é, há uma quantidade de material sobre os eventos ocorridos que descreve o que aconteceu em determinados encontros entre a educadora e seus alunos. A narrativa é organizada do seguinte modo e a organização desta análise seguiu a seguinte sistemática:

- a narrativa (propriamente dita), isto é, a descrição dos eventos, é guiada pelos argumentos e "áreas de sensibilidade". Seria muito cansativo e prejudicial para o desenvolvimento da narrativa repetir os argumentos completos, mas tendo em vista a necessidade de testar os argumentos de modo explícito, cada um deles foi sintetizado, a saber:

Quanto ao tema "adequação do modelo Fullan de liderança e mudança", cinco idéias são investigadas:

- propósito moral 
- entendimento da mudança

- construção de relacionamentos

- criação e compartilhamento de conhecimento

- estabelecimento de coerência

Quanto ao tema "teorização" feita pela educadora em seu percurso educacional, as seguintes idéias serão investigadas:

- criatividade

- insight

- bom senso

- sabedoria

Portanto, em seguida, por meio dessa técnica, foi feito um esforço para desenvolver simultaneamente a narrativa, os argumentos e as áreas de sensibilidade.

A especificação dos conceitos acima relatados - ou áreas de sensibilidade - ajuda a disfarçar a distância entre os argumentos operacionais listados na Introdução e os conceitos de liderança aqui revistos. A combinação dos argumentos operacionais com as "áreas de sensibilidade" possibilita atingir os seguintes objetivos: pelos argumentos operacionais obtém-se mais clareza e especificação e pelas "áreas de sensibilidade" é possível fazer com que a complexa teorização sobre liderança permeie a análise a ser desenvolvida a seguir:

\section{Análise do caso educacional}

Ao observar, em um ponto de ônibus, um grupo de alunos adolescentes da Escola Municipal Marc Ferrez, Mère Paternot sentiu que aqueles jovens pareciam "ovelhas desgarradas sem pastor". Procurou a Diretora daquela escola, que se situa na mesma região do antigo internato do Colégio Sacré
Coeur de Jesus, no Alto da Boa Vista, Rio de Janeiro, com o "propósito moral" de ajudar na educação dos alunos adolescentes. Este propósito não foi fruto de um desejo repentino que caracteriza um sentimento superficial. Havia um "comprometimento interno" que a animava nessa inusitada empreitada de sua vida. Desejava "fazer diferença na vida" daqueles adolescentes. Ficou sabendo, por professoras da escola, que os alunos adolescentes da favela eram revoltados, não queriam estudar e tinham comportamento insubordinado nas aulas. Embora com a idade de oitenta anos, a educadora não hesitou em enfrentar o desafio.

Sabia que seu primeiro encontro com os alunos seria decisivo. Optou por ser verdadeira, autêntica ou, segundo Fullan, criar um relacionamento autêntico com os alunos. Pediu que fosse chamada simplesmente pelo seu nome - Anne Marie. Disse aos alunos, para grande surpresa deles, que era professora voluntária, vinha como amiga e declarou que se preocupava com o presente e futuro deles, que os amava e respeitava - coisas que jamais alguém lhes dissera. Reconheceu explicitamente, para espanto deles, que eles tinham valores pelo o que eles eram.

Como mencionado anteriormente, os valores têm papel central no modelo Fullan. Em seu trabalho, Anne Marie cria um modo singular de operacionalizar liderança. Guiada por firme propósito moral de fazer diferença na vida daqueles jovens da oitava série, inicia encontros quinzenais com eles. Ao valorizar seus alunos, a educadora usa método semelhante ao preconizado pelo autor Gerard Egan (1973), em seu modelo de relacionamento interpessoal. Com palavras de acolhimento, a educadora toca profundamente os sentimentos do grupo de alu- 
nos, para então provocar seu interesse no desconhecido, no novo. Convida os alunos a assumirem a responsabilidade de gravar, em suas mentes e coração, o que ela denomina "livro" da Vida, uma ferramenta de aprendizagem que os ajudaria a abrir as portas para conhecimentos importantes para o futuro. Nesse primeiro contato com os alunos, a educadora tem o insight de deixar à escolha deles vir ou não às aulas.

A partir da segunda aula, a educadora consegue criar outros variados instrumentos de aprendizagem. Estimular os alunos a compartilhar idéias, medos, decepções com ela e com a turma. Este método visa orientar os alunos - geralmente dispersivos e sem nenhum interesse em aprender - a criar conhecimento de si próprios, dos seus colegas e do mundo e a compartilhar estes conhecimentos.

Em sua criatividade, usa algo simples, como o documento de identidade dos alunos, com o objetivo de que cada um se reconheça como um ser único com direitos e responsabilidades. Anne Marie não traz idéias prontas ou faz uso de teorias para dialogar com os alunos. Vai lenta e delicadamente fazendo com que eles exponham as idéias que têm na mente e reconheçam os sentimentos de seus corações. Ao descrever seu trabalho, em uma entrevista, diz que usa somente a velha maiêutica de Sócrates. Assim, constrói seu método de teorização. Em outras palavras, a educadora vai ganhando entendimento da mudança que pretende provocar na vida dos alunos.

Deve-se enfatizar o fato de a educadora tratar com alunos que vivem em ambiente de alto risco para formação moral. São jovens de 14 a 20 anos que desenvolveram comportamentos de pouca civilidade. Embora
Anne Marie dê a eles a liberdade de escolher os capítulos que formarão o livro da vida a ser construído, uma coisa não seria permitida nos encontros: eles não deveriam caçoar, zombar, rir se achasse ridículo o que foi dito por algum colega. Em todas as turmas, os alunos aceitaram de boa vontade esses limites, essa disciplina. Essa atitude da educadora mostra sua "coerência", ou equilíbrio, entre a exigência de disciplina e a amizade genuína por seus alunos.

A liderança de Anne Marie tem como finalidade transformar os alunos adolescentes, que se consideram um "lixo" (palavra dos próprios alunos) em líderes de sua vida e dos ambientes onde vivem. À medida que os encontros acontecem, o desejo dos alunos estarem com ela é cada vez maior. Já no terceiro contato, começam a escolher os capítulos do livro da vida que cada um construirá. Os temas escolhidos mostram que os alunos adolescentes das favelas pensam em coisas sérias.

Nos encontros seguintes, Anne Marie vai guiando um diálogo sobre os temas da lista, sejam eles o amor, o cotidiano ou a morte. Os próprios alunos criam oportunidades de distinguirem entre os temas que para eles representam bem ou mal. Essa estratégia de criar e compartilhar conhecimento, embora pareça simples, demanda muita sabedoria da parte da liderança. (No rumoroso crime praticado por alunos da escola Columbine, nos Estados Unidos, os pais da comunidade chegaram à conclusão que a principal necessidade dos jovens era ser educados para distinguir entre o bem e o mal). Sobre o tema amor, os alunos adolescentes favelados decidem focalizar o amor materno. Em contraposição a esse assunto, escolhem tratar do aborto. A dinâmica entre temas parte da iniciativa dos alunos. 
A criação de conhecimentos vitais para os jovens adolescentes é feita sem a necessidade de pregação que visa incutir determinadas idéias na cabeça dos alunos. Em se tratando de uma freira católica, de uma geração, classe social e cultura muito diferentes da condição dos alunos, seria natural que eles receassem que o curso fosse (na linguagem dos alunos) chato, pura pregação religiosa. Isto nunca acontece, porque Anne Marie sempre usa bom senso em seus julgamentos. Aproveita a "dica" dos alunos nas conversações para enriquecer o que eles dizem, o que eles propõem. Por exemplo, quando discutem sobre o medo, algo que Fullan diz estar presente na maioria dos processos de mudança, Anne Marie aproveita as respostas dos alunos para mostrar-lhes que o desconhecido é sempre temido. Aproveita a oportunidade para incentivá-los a ter coragem de abrir a porta de suas vidas, refletir, tomar decisões. A líder nunca se escandaliza com o que os alunos dizem, mas leva-os a refletir sobre o que disseram. Os diálogos sobre trabalho, política e medo exemplificam essa habilidade de Anne Marie construir e compartilhar conhecimento.

Com o passar do tempo, torna-se evidente que os alunos ficam mais à vontade para expor seus pensamentos. Isso indica que a líder educadora e os alunos estão plenamente entrosados. Não é provável que um grupo de adolescentes favelados teriam interesse em conversar com pessoas como Anne Marie. Nas sociedades e organizações atuais, as pessoas tendem a se agrupar por interesses e situações comuns. Com a nuclearização, seguida da crescente desagregação da família extensiva, os jovens ganharam uma pseudo-independência. Entretanto, por várias razões, perderam muitas oportunidades de absorverem a sabedoria de seus ancestrais. $\bigcirc$ resultado são jovens que se formam, principalmente, através da socialização com seus pares, isto é, outros adolescentes. No caso dos jovens alunos favelados, a maioria não tem alguém na família que os oriente para vida. Os diálogos de Anne Marie com seus alunos na escola Marc Ferrez são construídos com maestria para essa finalidade, sejam os temas trabalho, medo, amor política ou uso de droga. Para Fullan (2001), liderança efetiva é garantia de mudança de sucesso. Os alunos chegam à conclusão que "cada um é responsável por sua própria vida." A liderança de Anne Marie se efetiva nessa frase.

\section{Conclusão}

A seção acima testou, contra o caso educacional dos alunos adolescentes favelados, o problema e argumentos - originários do senso comum, e teorizados - levantados neste trabalho. Através dessa metodologia de análise, pode-se concluir que a educação dos referidos alunos, conduzida pela Irmã Anne Marie Paternot, tem mérito científico, embora não propositalmente estabelecidos pela educadora. A teoria de Michael Fullan sobre liderança e mudança valida vários aspectos da educação desenvolvida pela educadora, a saber:

- Fullan diz que casos de mudança são complexos, isto é, multidimensionais. Assim, também é a liderança efetiva da mudança. O caso em questão se apresenta como crítico, complexo. Os grupos de alunos adolescentes favelados apresentam comportamentos que criam obstáculos para sua aprendizagem e dos outros alunos da escola;

- A educadora desenvolve várias habilidades de liderança alinhadas com as dimensões de liderança do modelo Fullan; 
- A "teorização" da educadora é baseada em qualidades pedagógicas desenvolvidas ao longo de uma vida dedicada à educação;

- Sem ter esse propósito, a educadora operacionaliza, além das idéias de Fullan sobre liderança efetiva, as de outros autores mencionados no texto;

- A teorização da educadora baseia-se em convicções morais que permeiam suas relações com os alunos, o diálogo que estabelece com eles e entre eles, o cuidado com o sentimento dos alunos em uma cultura de mudança e a coerência entre todo o sistema de habilidades.

A análise também mostra que a educação dos adolescentes se desenvolve em estágios distintos. A educadora vai fortalecendo a ligação de confiança entre ela e os alunos até que possa seguramente confrontar alguns pontos que necessariamente têm que ser explicitados (essa teorização corre na mesma direção do modelo Egan, citado do trabalho).
A educadora declara que não usa teoria, mas usa a própria visão educacional, alimentada pela sabedoria acumulada, bom senso, insight, e especialmente criatividade. É uma teorização que se forma à medida que a ação se desenvolve. Cientificamente, pode-se argumentar pos-facto, que raramente poder-se-ia encontrar um resultado de pesquisa sobre liderança na qual todas as dimensões do modelo Fullan tivessem sido desenvolvidas, como no presente caso. Portanto, é possível concluir que o caso aqui apresentado valida o modelo Fullan e avança em teoria no campo de liderança e mudança.

Finalmente, há uma questão nesse trabalho que não foi explicitada: "o que significa e que efeito tem sobre liderança e mudança a 'essência do educador'?" $\bigcirc$ que deu origem a essa pergunta consta da conversa de Mère Paternot com uma ex-aluna, a conhecida educadora Maria Cecília Almeida e Silva (em anexo). Fica aqui a recomendação que futuros trabalhos, sobre os assuntos aqui tratados, explorem esta questão. 


\section{Referências}

CARLSON, R. O. Adoption of educational innovations. Eugene, Or.: Center for the Advanced Study of Educational Administration, University of Oregon, 1965.

CHIN, R.; BENNE, K. D. General stategies for effecting changes in human systems. In: BENNIS, W. G.; BENNE, K. D.; CHIN, R. (Ed.). The planning of change. $2^{\text {nd }}$ ed. New York: Holt, Rinehart \& Winston, 1969.

DRUCKER, P. F. The essential Drucker: selections from the management works of Peter F. Drucker. New York: Harper Collins Publishers, 2001.

Management challenges for the 21st. Century. New York: Harpper Business, 1999.

EGAN, G., The annual handbook for group facilitators. San Diego, CA: University Associates Press, 1973.

FULLAN, M. Leading in a culture of change. San Francisco: Jossey-Bass, 2001.

GETZELS, J.; W.; LIPHAN, L.; CAMPBELL, J. M. Educational administration as a social process. New York: Harper and Row, Columbia University, 1968.

GULICK, L. et al. Papers on the science of administration. New York: Columbia University, 1937.

MARRIS, P. Loss and change. New York: Anchor Press/Doubleday, 1975.

SENGE, P. M. The fifth discipline. New York: Doubleday, 1990.

TAYLOR, F. The principals of scientific management. New York: Harper \& Haw Publishers, 1911.

TOLLINI, I. M. Desafio da mudança educacional: criar e compartilhar conhecimento. In: SIMPÓSIO DA ANPAE, 3., 2003, Goiânia. Anais... Goiânia, GO, 2003a.

Liderança na educação em uma cultura de mudança. In: EPECO, 6., 2003,

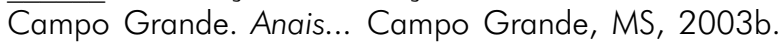

Novo significado de liderança e mudança em uma cultura de mudança. In: JORNADA LUSO-AMERICANA, 1., 2003, Brasília. Trabalhos apresentados... Brasília, DF, 2003c.

A volta da disciplina (conferência pronunciada na abertura). In: CONGRESSO PARANAENSE DE EDUCAÇÃO, 3., 2003, Curitiba. Anais... Curitiba, PR: SINEP, $2003 d$.

Recebido em: 30/06/2004

Aceito para publicação em: 06/02/2006 


\section{ANEXOS}

\section{Uma educação libertadora: a caminhada de uma educadora}

Anne-Marie Paternot

RSCJ

Rio de Janeiro, julho de 2003.

Fiquei feliz por encontrar nesse título o que corresponde exatamente ao que procuro fazer como educadora, tanto ao tratar com adolescentes moradores de favelas como ao dar aulas particulares a crianças e adolescentes de classe abastada. Para mim, sem fazer nenhuma discriminação, são todos seres humanos, sedentos de amor e compreensão, dignos de um tratamento individual correspondendo às riquezas que cada um traz dentro de si.

Nem pequenos nem grandes gostam de receber ordens, que geralmente mais correspondem ao modo de pensar de quem as dá do que à compreensão e convicção de quem as recebe, especialmente em se tratando de adolescentes.

Educar é ajudar cada um a descobrir suas falhas para corrigi-las ou suprimi-las. É orientar sobre o valor dos talentos próprios para desenvolvê-los e, baseado neles, alicerçar sua vida. Educar é auxiliar o favelado rejeitado, desprezado [...] a tomar consciência de seus valores para libertar-se do que o impede de enfrentar a vida com esperança, porque aprendeu a confiar em si mesmo e a respeitar-se como pessoa digna de respeito da sociedade.

Educar é criar laços de confiança, de amizade com o educando, é dar-lhe o que se deseja que ele dê aos outros.

Educar é transmissão de vida, de amor, de respeito pelo valor que cada ser humano leva em potência dentro de si.
Para educar, teorias fruto de conhecimentos indispensáveis, não são o principal. $\bigcirc$ principal, o essencial é o conhecimento do ser humano em profundidade, é o despertar dos sentimentos latentes, é tratá-lo como um ser único, um indivíduo capaz de desenvolver-se (Como?), de trabalhar (Em quê?), de gerar multiplicadores, de solidarizar-se com os necessitados, de irradiar felicidade, porque ele mesmo descobriu que o essencial em tudo na vida é o amor vivido, partilhado. É assim que Deus ama todos os seres humanos.

Educar assim não será um dos melhores meios, ou talvez o melhor, de livrarmos este mundo do que mais o aflige agora violência, terrorismo, ganância, egoísmo [...]?

\section{Conversando com uma sempre aluna}

Maria Cecília Almeida e Silva

Fundadora, Diretora Geral do Pró-Saber, Centro de Estudos Psicopedagógicos

Você tinha 13 anos quando eu era sua diretora, orientadora educacional e professora de francês. $\bigcirc$ que a marcou como adolescente nessa época?

- A extrema confiança que eu sentia de sua parte foi fundamental para que eu me visse para além dos rótulos normalmente colados nas adolescentes que pintam e bordam. Conseguia perceber que, apesar das aparências, eu era digna de confiança e precisava que me visse para além dos rótulos normalmente colados nas adolescentes que pintam e bordam. Conseguia perceber que apesar das aparências eu era digna de confiança.

\section{A Semana de Formação que sentido teve para você?}

- Minha primeira lembrança é de mui- 
to divertimento e alegria. Era uma semana inteira no final do ano, que passava voando. Hoje vejo que era muito mais que isso. Havia toda uma nova pedagogia em embrião: aprendizagem grupal, grupos de discussão, temas geradores, projetos [...]. Tudo isso acontecia num clima de autonomia, criatividade, responsabilidade, disciplina.

\section{E hoje como psicopedagoga o que diria do meu trabalho?}

- Diria do meu encanto diante de sua juventude. Diria da minha admiração pela sua trajetória pessoal de ousadia e criatividade. Acredito que mais do que reformas educacionais e novas metodologias o que conta é a essência do educador.

Muitos anos se passaram... A adolescente transformou-se na mulher que eu adivinhava nela. Hoje nosso relacionamento pode-se definir como amizade sempre crescente, baseada na mesma e antiga confiança.

\section{A caminhada de uma educadora: de 1940 a 2003}

Depois de ter lido o artigo "A volta à disciplina", da Dra. Ignez Martins Tollini, publicado no Diário Braziliense de 19 de maio de 2003, a pedido seu, tentarei dar uma idéia da trajetória de uma longa vida de educadora, sempre à procura de uma resposta a seus questionamentos, concordando plenamente com os últimos parágrafos:" $\bigcirc$ resultado desses extremos (antigo modo disciplinar excessivamente rígido - modo liberal sem disciplina e responsabilidade) talvez explique os eventos criminosos ocorridos recentemente nas famílias e na sociedade, tendo jovens como protagonistas". "Teremos que encontrar a mistura renovada de disciplina e amor tendo como base que o entendimento que disciplina é amor, um amor exigente".
Eis um pequeno esboço baseado na experiência vivida em contato com uma sociedade, um mundo flutuando de um extremo ao outro em matéria de educação, buscando soluções, reconhecendo fracassos, procurando finalmente, uma base sólida, a única capaz de tudo transformar e sustentar: amor, valorização de cada ser humano como único e responsável, digno de respeito e confiança.

Em 1940, tendo terminado meu noviciado no momento em que a França entrava em guerra, passei 6 meses em Roma, no colégio Sacré-Coeur da Trinitá dei Monti dando aulas, entre outras ocupações, a um grupo de filhas de diplomatas.

Experiência interessante e proveitosa, dada a diversidade de origem das adolescentes preocupadas com o ambiente de guerra que atingia, de modos diferentes suas famílias. Regressando ao Brasil, iniciando de fato, minha caminhada como professora no semi- internato, colégio Sacré-Cover do Morro da Graça, Rio de Janeiro, não conheci a rigidez disciplinar do início do século, provavelmente devido ao ambiente familiar e linha educacional adotada pela Congregação da qual sou membro. Havia disciplina, sim, e regulamento exigido em vista de profundo preparo para a vida e sólida cultura intelectual. Apesar de métodos pedagógicos tradicionais vigentes em nosso colégio, fui seguindo minha tendência, seguindo mais uma linha socrática e procurando conhecer a tendência de cada aluna. Nessa linha, conscientes de sua responsabilidade, vivem hoje mulheres que aprenderam a suportar dificuldades com coragem, profundo espírito cristão e gestos de solidariedade, tratando de adaptar-se às mudanças do mundo. 
A partir de 1948, depois de 2 anos passados numa Europa sofrida do após guerra, vim como Mestra Geral (cargo abrangendo funções de Diretora e Orientadora) do internato. Embora mantendo a disciplina pedida pelo regulamento de nossos colégios, tentei abrir horizontes para alunas oriundas, quase todas, de outros Estados do Brasil. Mais informadas sobre a situação do mundo ferido pela guerra, sentiram-se solidárias, mais maduras e responsáveis.

Sentia e percebia cada vez mais a necessidade de maior abertura e constante reflexão, num mundo em constante evolução. Também me dava conta da importância de cada ser humano com suas qualidades pessoais.

Experiência feita de 1952 em diante: Começo das férias, grupo de umas 25 alunas de $7^{a}$ e $8^{a}$ séries do semi-internato, optando livremente por "Uma Semana de Formação" no Alto da Boa Vista, organizando elas mesmas o horário, o tema a ser apresentado e discutido por elas, a organização dos lazeres (piscina, passeios na montanha, brincadeira depois do jantar) distribuição de tarefas, momento de oração... Decidiram que tudo devia ser feito com a possível perfeição por tratar-se de Dias de Formação. De tão certo, que a experiência foi repetida vários anos. Ao mudarem de Mestra Geral, pediram para continuar, mas não foram além de um só ano, porque tudo se fazia sem prévia organização, já não havia sentido de "Formação", de uma "disciplina que é amor, um amor exigente".

\section{7: uma experiência bem atual, bem diferente}

Com quem? Alunos das $8^{a}$ s séries de uma Escola Municipal, moradores de favelas.

Para quê? Para que, tomando consciência de seu valor pessoal, deixem de se considerar excluídos da sociedade, sintam-se responsáveis por sua própria vida, capazes de serem agentes de progresso no seu próprio ambiente.

Como? Através de contatos quinzenais, dentro da Escola, quando a Orientadora vem como amiga, movida pelo amor e respeito que tem pelos jovens. É tudo na base do diálogo, da conversa informal onde, com toda a liberdade e respeito mútuo, cada um dá sua opinião sobre temas escolhidos pela turma toda. Tema fundamental: A VIDA, cujo livro cada jovem irá gravando em sua mente e em seu coração à medida que se apresentarem os capítulos, aceitando o que julgar ótimo, necessário, prático [...]. Ou, ao contrário, nocivo à VIDA porque a destrói. As conclusões brotam dos próprios adolescentes, aceitas para serem vividas.

\section{Orientação educacional na Escola Municipal Marc Ferrez}

Alto da Boa Vista, Rio de Janeiro

- Como surgiu?

- Foi em 1997, na parada de ônibus do Alto da Boa Vista. Chamou-me atenção aquele bando de jovens barulhentos, perigosamente expostos ao trânsito intenso por suas brincadeiras de mau gosto, invadindo a pista e atropelando-se ao entrar no ônibus. Pareciam "ovelhas sem pastor".

- Quem os educava? Quem os orientava no momento presente em vista do futuro? Resolvi falar com a Diretora da Escola, indagando se ali havia alguém que se ocupasse desse setor.

- Infelizmente, não. Nenhuma Escola Municipal do Rio de Janeiro dá esse atendimento aos alunos.

- Como Orientadora Educacional isso me preocupa.

- Então, por favor, venha colaborar conosco dando-lhes orientação. 
- Como Orientação Educacional não se dá, não se pode impor, são jovens que vão se orientar-se eles mesmos, agora e no decorrer da vida, baseados no conhecimento de meios que os ajudarão para tal. Por isso, só poderei aceitar de vir colaborar aqui com uma condição: Que esses jovens das $8^{a} \mathrm{~s}$ séries desejem se orientar sob todos os aspectos. Se me for permitido, terei um encontro com cada turma e virei, com prazer, para quem o desejar.

- A senhora viria como voluntária?

- Sem dúvida.

Dias depois, primeiro contato com cada uma das quatro turmas de $8^{a}$ série, compostas de adolescentes de 14 a 19 anos, quase todos moradores das favelas do Borel, da Formiga, de Mata Machado e adjacências.

\section{O que é orientação educacional: o que disseram os jovens na avaliação do ano $\mathbf{2 0 0 0}$}

- É aprender a enfrentar os obstáculos que a vida nos proporciona e ver os problemas com mais facilidade. Aprendemos a Ter respeito e Ter mais vontade de ser alguém na vida. E também nos ajudou a escolher nossa profissão.

- É aprender a viver de um modo simples até que todos percebam que você é diferente. É conseguir vencer em todos os obstáculos. É orientar as pessoas quando elas mais precisam.

- Achamos legal porque nos ajuda a tirar muitas dúvidas. Gostaríamos que outras escolas tivessem a oportunidade que temos. Conversando sobre: sexo, drogas, amor, família, violência, ou seja, sobre o nosso futuro. Nossa orientadora é uma pessoa de bom coração que nos orienta porque nos ama. Queríamos ter mais tempo para dialogar com ela.

- É uma lição de vida. Aprendemos a ter força de vontade em tudo aquilo que fazemos, até mesmo pelo exemplo que ela nos passa.

- Vale a pena ouvir o que você tem a nos dizer e a nos ensinar, pois ganhamos muito com isso, porque é difícil alguém nos entender e acreditar que poderemos um dia nos tornar pessoas capazes de compreender as outras e de simplesmente sermos felizes. Anne-Marie vem porque ama os jovens.

- Orientação de amor profundo e verdadeiro.

\section{0 contato com as turmas da 8a série da Escola Marc Ferrez}

Jovens de 14 a 20 anos, quase todos moradores de favelas

- A senhora vai ser nossa professora? De que matéria?

- Não venho ensinar e sim dialogar com vocês.

- Mas a senhora não é professora?

- Sim, mas aqui sou sua amiga e prefiro que me chamem simplesmente pelo meu nome.

- Então por que veio aqui? Vai ganhar dinheiro?

- Venho como voluntária e, para mim, sua amizade vale mais que dinheiro.

- Não vai ensinar, não vai ganhar dinheiro, então por que veio?

- Porque amo os jovens com quem trato há mais de 60 anos [...]. Amo vocês.

- Preocupo-me com o seu presente e o seu futuro, quero que sejam felizes. E também venho porque respeito vocês.

- Como? Você respeita a gente? Não é possível!

- Respeito sim, por sua vitalidade, sua força em plena juventude, sua personalidade em formação, sua capacidade de melhorar o bairro, o Rio, o Brasil, o mundo. Porque o amor está borbulhando dentro de cada um de vocês e espero que aprendam a orientá-lo em vista de sua felicidade, sem desperdiçálo, sem jogá-lo na droga. É isso mesmo, res- 
peito vocês pelos valores que possuem, pelo que vocês são. (Vários choram [...] Nunca alguém thes havia dito que os respeita).

- Que valores?

- A pessoa não vale pelo dinheiro que tem no banco ou no bolso. Vale pelo que é. Todos, com ou sem dinheiro, possuem dentro de si riquezas e misérias. Com uns que têm dinheiro, a quem dou aulas particulares, falo de ambas e têm pouco dinheiro, falaremos principalmente de suas riquezas, vamos descobri-las juntos, conversando entre amigos. De suas misérias, já ouvem falar bastante por gente que diz algumas verdadeiras e muitas falsas, são calúnias feitas por quem generaliza injustamente.

- Não precisam comprar livro para nossos encontros. Todos já o têm.

- É a Bíblia?

- Não. Não venho ensinar-lhes religião. Embora seja católica, como o sabem não me preocupo com que crença seja a sua, contanto que pratiquem sua opção e a vivam a fundo, com convicção. $\bigcirc$ pior é não crer em nada.

- Mesmo os povos mais primitivos têm seu modo de louvar a Deus e olhar para algo superior, não se arrastando pelo chão como minhocas ou lesmas.

- BRRR [...]

- Acham horrível viver como lesma? Pois depende de vocês. Cada um já está com idade de assumir responsavelmente sua própria vida.

- Então, qual é o livro?

- É sua vida. Mas os capítulos desse livro a ser gravado em sua mente e em seu coração terá os capítulos que vocês escolherem como assuntos para nossas conversas.

- Vamos ter que escrever?

- Não. Raramente se volta a ler o que está escrito no papel. É o que se assimilou pessoal- mente que vai servir para vocês se orientarem agora e no futuro. Não sou eu que oriento, é cada um que se orienta livremente.

- Se quiserem, virei para a turma e, mesmo se alguém não o desejar, é livre de não vir tomar parte nas conversas. Não haverá nem chamada nem nota.

E todas as turmas optaram por ter orientação educacional.

\section{0 contato: quem sou eu?}

\section{Analisando a carteira de identidade}

- Qual o primeiro elemento?

- Número.

- Há quem passe pelo mundo como um número e nada mais. Não toma consciência de suas potencialidades, não desenvolve sua personalidade, não deixa rastro, nada. É identificado como um número para tudo: registro civil, chamada na escola, carteira de trabalho, INSS, endereço, telefone... e até no túmulo terá um número! Quem se considerou apenas número, "só passou pela vida, não viveu!"

- E depois?

- Data de expedição.

- Quem ainda não tirou carteira de identidade faça-o o quanto antes para começar logo a ser cidadão ou cidadã do Brasil.

- Agora, o nome.

- X da Silva.

- O que é mais importante: $X$ ou Silva?

- É X [...]. É Silva.

- É o sobrenome porque, ao ser gerado, já era um membro da família Silva, nome que você deverá honrar toda a sua vida, nunca manchá-lo. Depois, registraram este ou esta Silva com um nome que lhe é próprio: $X, Z$ [...] $\bigcirc$ nome escolhido por seus pais, com $\circ$ qual o registraram, vai distingui-lo dos outros Silva. Você, X da Silva, será reconhecido como alguém e não como número. 


\section{Filiação:}

- Um pai, uma mãe a quem você deve a vida, iá que através de um ato de amor (tomara que assim tenha sido para cada um de vocês), eles transmitiram o Dom que só o Senhor da vida pode dar. Espero e desejo que todos vocês sejam frutos do amor. Infelizmente há tantas crianças gerada por descuido, violência, curiosidade, leviandade, na bebedeira, na droga ou quem sabe o que mais [...]

- Quem é mais importante: o pai ou a mãe? A mãe, a mãe [...] o pai.

- Ambos têm a mesma importância. Sem ela, ele não seria pai. Sem ele, ela não seria mãe.

- Vamos analisar o papel de cada um, não para julgar como agem seus próprios pais e mães, mas para pensar no que vocês devem ser no futuro ao criar uma família.

- Pai; Que responsabilidade na educação, sustento, encaminhamento, orientação dos filhos e filhas. Ser amigo, mas saber fazer-se respeitar.

- Mãe: tão importante quanto o pai na geração dos filhos. Em seu útero desenvolveu-se a vida, em seu seio a criança encontrou seu alimento, em seus braços manifestou-se a ternura, e quantas vezes cabe à mãe trabalhar para sustentar os filhos! Seja como for, aos dois se deve respeito filial, mesmo não aprovando algo em sua conduta pessoal.

\section{Naturalidade:}

- O Brasil, o Estado, a cidade onde nasceu merecem patriotismo, dedicação, trabalho, esforço pessoal para seu progresso. Prepare-se para senvi-lo, para realizar o que depende de você para colaborar na sua construção, ainda que seja começando por um serviço pequeno e humilde. $E$, se cada um agir assim, quanta riqueza poderá ser aproveitada, quanta beleza será preservada e admirada nesse país gigante abençoado por Deus, que poderia e deveria ser o celeiro do mundo! [...]

- Rio de Janeiro: cidade maravilhosa, privilegiada entre mar e montanha, florestas e lagoas. Que pode fazer cada carioca para ter uma cidade ainda mais acolhedora, mais limpa, menos violenta? O Brasil, - Rio de Janeiro só podem mudar se eu, cada um de nós, tomar a peito sua responsabilidade e seu amor à Pátria.

\section{Data de nascimento:}

- Alguém aqui gostaria de ter nascido em outra época?

- Não, não [...]

- Então, se está satisfeito de ter nascido no fim do milênio, considere-se cidadão do século XXl e prepare-se para desempenhar seu papel dentro da História de sua Pátria e do mundo.

- Certamente não, mas é interessante viver numa época de grandes transformações, de invenções importantes dentro do progresso da humanidade, de empenho pela paz quando muitos só pensam em violência e terrorismo.

- Qual será a causa disso?

- É a ganância desenfreada pelo poder e o dinheiro.

- Como será você na idade adulta? Criador de algo novo, cooperador no desenvolvimento e aperfeiçoamento do que vai aparecendo... ou simples robô que só sabe apertar botões? É o momento de medir suas possibilidades e preparar-se para um futuro promissor.

\section{Documento de origem:}

- Geralmente é a Certidão de Nascimento. Verifique se está correta, sem erro que possa causar-Ihe dificuldade mais tarde. Ajude seus vizinhos e conhecidos a tirarem sua própria certidão e a dos filhos. Há gente que, por descuido ou ignorância, oficialmente não existe. 


\section{Fotografia:}

- Essa cara é a sua atualmente, sempre foi assim?

- Não. Já tive cara de neném, de criança.

- Será igual a esta quando tiver 40, 60 ou 80 anos?

- Certamente não.

- Todas as células do corpo mudam a cada 7 anos e você nem percebe.

- Sabia disso?

- Sim, aprendemos nas aulas de biologia.

- Então se seu rosto mudou, todas as células são outras, Manuel, você ainda é o Manuel que nasceu há 16 anos?

- Claro que sim.

- Todos têm certeza disso?

- Sim.

- Prova de que somos algo mais que nosso corpo, somos mais que pura matéria. Desde que nasceu você é você e o será sempre. Algo espiritual existe em nós mesmos depois que o corpo desaparece.

- Para que serve o corpo? Vamos analisar hoje apenas o rosto. Que acham?

- Serve para nos identificar, para manifestar sentimentos: riso, choro, olhar com interesse, amor ou ódio.

- É. Quantas vezes apenas um olhar, um sorriso basta para encorajar alguém que espera sua ajuda.

\section{Polegar direito:}

- Um enfeite? Um borrão $\bigcirc$ que é?

- São as impressões digitais, um dos principais instrumentos de identificação.

- Por quê?

- Porque cada pessoa as tem diferentes. Cada ser humano tem suas próprias linhas, é único. Conclusão: Fui criado como um ser único, eu sou eu e como tal sou responsável pelo que fizer de minha vida. $\bigcirc$ que eu deixar de fazer, ninguém o fará por mim pois, tenho meu papel a desempenhar neste mundo.

\section{Assinatura do titular:}

- Olhe bem para a sua Carteira de Identidade, verifique item por item e, se estiver de acordo, assine quer dizer: agora sei quem eu sou e assumo tudo o que sou.

\section{0 contato: o livro de minha vida}

Depois de nossa primeira conversa, a turma optou por ter encontros de Orientação Educacional, respeitando porém a liberdade individual dos que não desejassem assistir.

O segundo encontro tentou levar cada um de vocês a perguntar-se: Quem sou eu? Através da Certeira de Identidade, aprofundamos cada item e assinamos no final, cientes de que: eu sou eu, diferente dos outros por minhas características pessoais, minha origem, vivendo nesta época, neste país, responsável por cuidar de minha vida. Conversas quinzenais vão ajudar cada um a escrever "O livro de sua vida", isto é : como desejo que ela transcorra, para chegar à Felicidade.

Como nos livros didáticos há capítulos menos interessantes que gostaríamos de eliminar, vocês mesmos vão escolher os capítulos que desejam aprofundar no livro de sua vida, propondo-os com toda a liberdade: uns lindos, cativantes, matéria de muitos sonhos. Outros, são valores pessoais, podendo tornar-se palpitantes se tratados na base de um ideal apoiado e movido pelo esforço na luta por alcançar a vitória. Finalmente aqueles que matam a vida.

Uma só coisa será proibida nestes encontros: caçoar, zombar, rir se achar estranho, ridículo... o que foi dito por algum colega, porque tiraria a liberdade dele e o calaria. Todos merecem ser ouvidos, respeitados. 


\section{Que passos vamos seguir} para elaborar esse livro?

$1^{\circ}$ Escolha dos capítulos;

$2^{\circ}$ Reflexão partilhada entre todos, com toda a liberdade, através do diálogo;

$3^{\circ}$ Atenção durante essa troca de idéias e experiências pessoais para cada um ir se perguntando: Aceito esse modo de pensar, de agir?

Isso não me parece "legal", rejeito.

Vai custar, mas vou tentar viver assim.
Lutarei, mas não aceitarei essa atitude, esse vício.

E assim por diante, aceitando, rejeitando, assimilando $[\ldots]$ construindo meu ideal de vida.

Assim poderei chegar a escrever o "Livro de minha vida", não no papel, mas na cabeça e no coração, onde não há perigo de esquecer e força para praticar lutando contra os obstáculos para viver de fato como acho que devo viver.

\section{Capítulos do " Livro da vida"}

\begin{tabular}{|l|l|l|}
\hline AMOR & COTIDIANO & MORTE \\
\hline Sexo & Saúde & Violência \\
Vida após a morte & Coragem & Drogas \\
Namoro & Convicções & Guerra \\
Família & Força de vontade & Fome \\
Deus, religião & Lazer & Prostituição \\
Amizade & Trabalho & Mentira \\
Honestidade & Estudo & Traição \\
Felicidade & Profissão & Rivalidade \\
Fidelidade & Circunstância & Ambição \\
Solidariedade & Desemprego & Egoísmo \\
Dignidade & Cidadania & Inveja \\
Responsabilidade & Meio ambiente & Adultério \\
Vocação & Programa & Infidelidade \\
Compreensão & Elegância & Aborto \\
Coragem & Mídia & Pedofilia \\
Casamento & Educação & Favelas \\
Maturidade & Relacionamento & Terrorismo \\
Adolescência & Jogos & Miséria \\
Obediência & Esporte & Desemprego \\
Carinho & Televisão & Ódio \\
Paixão & Leitura & Clonagem \\
Humildade & Política, governo & Preconceitos \\
Coleguismo & Sucesso & \\
Personalidade & Personalidade & \\
Fraternidade & Capacidade & \\
Vida & Lazer & \\
Lealdade & Comunicação & \\
Humanidade & Abertura ao mundo & \\
Esperança & Ecologia & \\
Confiança & Liberdade & \\
Prazer & Realismo & \\
\hline
\end{tabular}


Escrevendo o "Livro da vida": alguns flashes de conversas

- Vamos continuar falando sobre amor.

- Ótimo!

- Sob que aspecto?

- Amor materno, porque tenha uma fiIhinha que é o amor de minha vida.

- Você vai nos ajudar a compreender melhor esse amor, que já começa desde que, num ato de amor entre um homem e uma mulher, a semente começa a brotar no útero. Como se sentiu então?

(A jovem mãe foi respondendo com simplicidade às perguntas dos e das colegas que a escutavam com respeito e interesse. Falou da alegria de sentir o feto crescer, do primeiro ponta pé que sentiu com emoção, do momento em que a criança quis entrar no mundo [...]).

- Foram horas de muito sofrimento, em que não poupei esforços para ajudá-la a nascer. Enfim, meu coração estremeceu ouvindo o choro dela ao entrar no mundo, ao senti-la precisando ainda do calor de meu corpo.

- E aí, ela ficou calada?

- Sim, até que, depois de arrumadinha, abracei-a com ternura. Só chorou bastante quando sentiu fome. Dei-lhe o peito e ela chupou, chupou [...]

- Vocês já viram um neném mamando?

- Sim, claro!

- $\bigcirc$ que notou?

- Depois de algum tempo, começa a sorrir, a acariciar o seio da mãe.

- É a primeira manifestação de amor da filha que, embora inconscientemente, começa a corresponder ao amor da mãe que a acompanha desde que foi concebida.

(Momento de atenção silenciosa da turma toda, até que um rapaz se manifesta).
- Não compreendo, não posso compreender como é possível que haja mulheres que tiram o filho que conceberam, antes de nascer!

(Silêncio profundo na sala. Depois de um tempo em que os sinto refletindo, emocionados, finalmente falo, emocionada também):

- Vocês escolheram, entre outros assunto a tratarmos junto, o do "aborto". Já está explicado, em contraposição com a maravilha do amor materno. Mas, não vamos generalizá-lo como sendo sempre um crime. Se a semente brotou sem ser fruto de amor, por estupro, leviandade, ignorância [...] é lamentável, contra a natureza. Mas também pode ser um ato de desespero de uma mãe sem recurso para criar um filho. Não vamos julgar nada levianamente. Vamos pensar agora, agradecendo a $\mathrm{X}$ pelo testemunho que nos deu do seu amor pela filhinha que maravilha é o amor materno!

\section{Trabalho}

- Para quê?

- Sobreviver [...] Ganhar dinheiro [...] Ter posição na vida [...] Matar a fome [...]

- Supõe o quê?

- Oportunidade, emprego[...] Vocação [...] Profissão [...] Estudo [...] Experiência.

- Qualidades pessoais?

- Força de vontade, respeito, obediência, pontualidade, honestidade, disposição, facilidade de transporte, boa aparência, bom relacionamento, amizade, gosto pelo que faz (cada item foi amplamente aprofundado entre todos).

- Em quê?

- Está difícil encontrar um emprego, que se pega o primeiro em que se for aceito.

- E podendo escolher?

- Pelo gosto, pela disposição, pela facilidade, por minhas habilidades, tendências $[\ldots]$ 
- Então, vamos trocar idéias sobre vocação, profissão, estudo [...] no nosso próximo encontro.

\section{Medo}

- $O$ que lhes causa medo?

- $\bigcirc$ escuro, a violência, a morte (muitos) [...] não ter uma vida feliz, meu pai, [...].

- O motivo do medo é o mesmo para todos: o desconhecido.

- Vocês, adolescentes, encontram-se diante de uma porta ainda fechada sobre sua vida. Como será? $\bigcirc$ que farei? Terei êxito ou fracasso? E no amor, essencial em tudo na vida para lhe dar sentido e força para vencer obstáculos e encontrar a felicidade. Está na hora de cada um abrir essa porta, refletir, tomar decisões, orientar-se com prudência, liberdade, esforço, esperança. Preparar agora a vida olhando para o futuro.

- E o medo vai passar.

- Depende das circunstâncias e das disposições com as quais você irá abrindo a porta. À medida que for procurando caminhos e tomar decisões, poderá eliminar ou pelo menos atenuar alguns deles.

- Tenho medo de dar passos errados agora que tenho que decidir. Onde cursar - $2^{\circ}$ grau? Que profissão escolher?

- Eu não tenho esses dois medos. Vou para o Quintino no ano que vem e depois ao mesmo tempo, sigo um Curso Profissionalizante, para já poder ir trabalhando enquanto estudo.

- Eu gostaria de ser professor, mas já desisti porque o solário é insuficiente e a vida deve ser muito cansativa, com poucas compensações.

- A gente pensa no futuro, mas ainda tem que suportar algumas matérias tão inúteis dentro da carreira que se pretende seguir!
- Se vocês tentarem pôr interesse em cada matéria do programa, lendo sobre o assunto, pesquisando pessoalmente, compreenderão a utilidade de tudo o que desenvolve o raciocínio. Este fato ajudará a compreender a necessidade do que nos parece inútil: Ao visitar um prédio em construção vejo uma quantidade de ripas de madeira jogadas num canto e grandes reservatórios de água perto de belas colunas redondas que sustentam o edifício. Nas colunas, nem água, nem madeira, mas sem estes dois elementos, nada poderia ser construído.

- É. Então o jeito é agüentar mesmo as matérias chatas [...]

- Você não gosta de química e eu sim. Eu detesto história e você vive pesquisando sobre assunto.

- Com o tempo a gente vai ver que, gostando ou não, o esforço nunca é perdido e que dificuldades vencidas ajudam a gente a aprender a viver e vencer na vida.

Dialogando sobre droga, saúde e responsabilidade

- Para você, qual a primeira palavra que se associa à droga?

- É morte.

- Por quê?

- Porque quem se droga acaba morrendo disso.

- Porque quem passa droga se arrisca a ser morto.

- Porque quem sabe demais sobre os pontos de droga pode ser assassinado para não revelar à polícia ou a grupos rivais.

- Então é inocente?

- Não, porque está sob o efeito da droga que tomou livremente, por isso é responsável pelo homicídio.

- Com que idade vocês acham que um jovem começa a se drogar? 
- Pelos 14 anos.

- Não! Muito antes! Já vi crianças de 8 anos drogadas.

- Pois eu já vi até de 5 anos, porque usaram o menino como "aviãozinho" e, aos poucos, foram viciando a criança para que mais tarde se juntasse ao grupo deles sem denunciar.

- Mas por que crianças tão novinhas?

- Porque até os 14 anos a polícia não pode fazer nada contra elas e, depois dessa idade, os que não tiverem aderido ao grupo dos traficantes são mortos e os corpos geralmente são jogados na valeta da favela. Aí formiga come [...]

- Que tem a ver droga com a saúde?

- Aos poucos, a droga vai estragando a saúde.

- Overdoses matam.

- Que é isso que você disse?

- É a expressão inglesa que usam pra dizer que tomou droga mais da conta.

- O drogado pratica atos inconscientes, dos quais é responsável e, nesses momentos, pode pegar AIDS ou outras doenças

- Por isso é que deve usar a camisinha?

- É sim.

- E evita mesmo de pegar AIDS?

- Dizem que sim. A gente não vê na televisão, não ouve no rádio quantas propagandas fazem insistindo no uso da camisinha, agora tanto para os homens como para as mulheres?

- $\bigcirc$ que tem a ver a droga com a responsabilidade?

- O drogado, assim como o bêbado, perde voluntariamente sua liberdade.

- Sua personalidade age como se não tivesse responsabilidade.

- O drogado está renunciando à sua liberdade.

- Tem razão. O ser humano é livre quan- do tem o uso da inteligência para distinguir o que é um bem do que é um mal e sua vontade lhe dá forças para escolher o bem. Há pessoas escravas da bebida, da droga, do cigarro e de tantas outras coisas [...]. Daí para pensar.

- Quem de vocês quer ser escravo?

- Querem desenvolver sua inteligência através do estudo, seu corpo com a atividade física, o esporte, mas procuram fortalecer sua vontade para conseguir dominar-se quando foi necessário resistir a algum vício?

- Acham que um viciado pode livrar-se da droga?

- Acho que sim e dou testemunho disso. Tenho 17 anos e já fui vítima da droga. Quando descobri que estava matando a mim mesmo, fiz um esforço danado e consegui.

- Logo, afirmo que quem quiser, de verdade, pode deixar de ser viciado.

- Que conclusão tiramos dessa nossa conversa?

- Que cada um é responsável por sua própria vida.

\section{Governo - Política}

Assunto pedido em vésperas de eleições

- $\bigcirc$ Brasil é Pentacampeão no Mundial de Futebol. Com certeza seguiram tudo na $T V$, torcendo, vibrando, desejando a vitória.

- Foi sensacional! Fomos vencendo todos os adversários apesar das dificuldades.

- A quem devemos esse sucesso?

- À garra dos jogadores, orientados pelo técnico Luiz Felipe Scolari.

- Que qualidades fizeram com que se tornasse o Felipão do Penta?

- A perseverança, o trabalho, a coragem com que enfrentou o caos do futebol brasileiro.

- Criou um clima de amizade, carinho, união [...] Fundou a "Família Scolari", cuidando dela como um pai cuida dos filhos. 
- Também teve o rigor necessário para impor disciplina, obediência.

- Vamos escrevendo no quadro esta e mais qualidade que acharem.

- Criatividade, competência, organização.

- Acham que ele procurava antes de tudo uma vitória para a Seleção?

- Parece que ele disse: "Não quero que entrem em campo se sentindo na obrigação de vencer".

- É. Foi quando o time chegou às quartas de final. Ele aí disse também: "Já chegamos até aqui, se não vencermos já está bem, mas joguem o melhor que puderem".

- E depois da Conquista do Penta, o final foi lindo: Todos abraçados num grande círculo, dando graças a Deus.

- Vocês citaram quase todos os requisito que fizeram de Luiz Felipe Scolari o "Felipão". Agora, vamos ler trechos de um artigo de Leonardo Boff (Jornal do Brasil, 6 de julho de 2002): "Se tivermos um presidente Felipão, seguramente o destino social de nosso país será diferente e melhor. Por isso elejamos um presidente que ostente as virtudes de Felipão" [...] "Precisamos de um presidente que escute o povo, pois tem sábias lições a nos dar, de como sobreviver a todas as tribulações mantendo a alegria de lutar e de viver".

- Que tal escreverem este capítulo 9 do livro de sua própria vida, com o título: Governo e Política?

- Ótimo. Dá para pensar e agir. Com um Presidente da República assim, nós também poderemos ser uma Seleção Penta.

\section{Síntese da avaliação

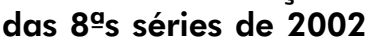

- "Foi um modo de aprendizagem muito bom enquanto durou.

- Foi bom porque eu acho que colocou juízo nos jovens da turma.
- Nós aprendemos muitas lições de paz.

- Nós aprendemos muito com a senhora, aprendemos a enxergar a vida bem melhor.

- Anne-Marie é uma senhora muito educada. Valeu a pena o tempo que a gente passou com ela.

- Nós aprendemos muitas coisas, coisas que a gente nunca aprendeu, que não nos ensinaram.

- Sobre o livro da vida. Anne-Marie sabe tudo, Valeu, Anne-Marie, valeu a pena. Foi bom enquanto durou.

- Durante os nossos encontros com a nossa amiga Anne-Marie, vivemos uma experiência excelente. Antes, ninguém pensava no futuro claramente, só depois que ela veio para nossa escola.: Aprendemos que a dignidade vem em $1^{\circ}$ lugar, em seguida, educação, respeito, confiança em si próprio entre outras coisas. Como amigos dela na $8^{a}$ série, indicamos ela como uma boa instrutora de educação e amiga para a $8^{a}$ como para todas as turmas da escola. Todas as escolas deviam ter uma pessoa como AnneMarie. Beijos. Sentiremos saudades. São os alunos da Marc Ferrez 27.11.2002.

- Neste tempo que estivemos na Marc Ferrez, aconteceram muitas coisas boas. Mesmo que às vezes as pessoas não prestavam atenção foi legal. Eu aprendi a importância da amizade, o conhecimento do trabalho.

- A importância da amizade, dos estudos, do trabalho. Sinto o amor dentro de mim. Eu gostei das histórias. Eu admirei seu trabalho aos 87 anos. Foi ótimo o seu trabalho!

- Parabéns!

- Aprendemos que a vida não é só ale- 
gria, mas tem seus momentos difíceis, de luta e dificuldades. Aprendemos a respeitar o próximo e também amar uns aos outros. E que o amor é o essencial em tudo na vida.

- O ensino que eu aprendi com a AnneMarie, neste ano e o que vai ser para o meu futuro, para quando eu precisar eu vou me lembrar do que ela me falou. Talvez cada um se ponha no seu lugar.

- Que todos tenham por exemplo AnneMarie, o que fez por nós, o que ela nos ensinou para o nosso futuro, para toda a vida aprendi com ela.

- Aquilo que nós conversamos na sala, aqueles que prestaram atenção em você e seguir os seus conselhos será alguém na vida. $\bigcirc$ que ela quer é o melhor para nós e para sociedade.

- Aqueles momentos que nós passamos com ela, foi ótimo. Que como tudo começou, tudo acabe!

- Valeu a pena ficar com você este ano. Aprendi muitas coisas para o nosso futuro e também para a nossa saúde é muito importante. Sei também que não é legal usar drogas para não causar nenhum problema no meu futuro.

- De tudo que a senhora me ensinou eu aprendi um pouco. Essa aula valeu muito.

- Espero que você venha ano que vem para outras pessoas aprenderem também.

- Eu acho as aulas da senhora muito boas, foi muito bom enquanto durou.

- Nós refletimos muito nas aulas da senhora. Espero que a senhora seja muito feliz.

- Bom! Nós achamos que tudo foi proveitoso, de tudo tiramos uma conclusão e respeitamos a cada nova idéia e sentimento. Sobre os assuntos, todos maravilhosos, lamentamos por não podermos falar sobre outros também importantes. Foi ótima experiência com a senhora e esperamos que a senhora tenha força e que a sua felicidade não acabe e que continue ajudando a outros jovens como nos ajudou. Gratas eternamente.

- Hoje, nós sentimos o amor, a paz, o reconhecimento da vida, a união entre as famílias, união entre os amigos, a humildade entre irmãos e sabemos que não podemos estragar as nossas vidas porque sabemos que ela é muito preciosa e não podemos estragá-la.

- Aprendemos que a vida não é só alegria, mas tem seus momentos difíceis, de luta e dificuldades. Aprendemos a respeitar o próximo e também amar uns aos outros. E que o amor é a essência em tudo na vida.

- Anne-Marie você é uma pessoa tão especial, que nos ajudou a compreender mais a vida, nos ensinou a tomar atitudes, que temos que ter responsabilidade. Nos ensinou a ter respeito e nos respeitou. É uma amiga, é mãe, é tudo de bom. Gostamos de ouvir suas histórias. Por tudo isso nós dizemos muito obrigado e com certeza como você nos ajudou vai ajudar outras pessoas.

- Beijos de Tamyres, Fernanda, Edson e Rosana".

Obs.: A terceira parte deste trabalho de pesquisa está em andamento.

Ignez Martins Tollini

Brasília, 15 de maio de 2006. 